\title{
Cultura y violencia y crítica al Estado-nación
}

\author{
Sergio Lomelí Gamboa
}

\author{
Notas sobre Cultura y violencia de Carlos Oliva \\ y Crítica al Estado-nación mexicano de Ambrosio Velasco, \\ en Mariflor Aguilar Rivero, coord., Sujeto, construcción \\ de identidades y cambio social. México, UnAM, 2008.
}

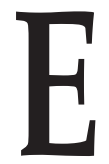

sta breve reseña de los textos mencionados en el título, pretende invitar al lector a que se acerque al libro Sujeto, construcción de identidades y cambio social coordinado por la doctora Mariflor Aguilar Rivero, como una buena muestra de la producción teórica de la Facultad de Filosofía y Letras de la UNAM. Los dos trabajos a los que se hará referencia se encuentran en este volumen colectivo de investigación. El presente trabajo sólo busca dar una probadita de los textos, y no exponerlos ni examinarlos exhaustivamente, de manera que se procura sólo exponer algunas de las tesis filosóficas más relevantes. Vale la pena mencionar que aun cuando se trata de dos textos que abordan temas distintos y desde tendencias filosóficas diferentes, ambos, desde mi perspectiva, responden a una realidad común, a saber: que vivimos tiempos violentos. Presenciamos una época en que la violencia es tan cotidiana que casi estamos acostumbrados a ella, y en muchos casos la consideramos "normal". A continuación mostraremos lo que estos autores nos dicen al respecto.

El texto Cultura y violencia de Carlos Oliva pretende hacer un cruce, como su título lo indica, entre estos dos conceptos. La definición de cultura que propone Oliva tiene tres características de interpretación principales, que son: la distinción entre cultura y naturaleza, la cultura como artificio, y la cultura como una agónica-erótica. Éstas serán expuestas muy brevemente a continuación.

La primera característica de cultura, heredera de la Ilustración, el romanticismo e historicismo establece ciertos procesos: el cultivo de capacidades individuales, el establecimiento de un sistema de artes y la formación de un humanismo. Oliva señala que desde su nacimiento, el concepto de cultura se opone a la posibilidad de interpretación histórica que privilegia el sentido comunitario, poniendo atención sólo, o principalmente, a la formación y desarrollo de capacidades individuales. Oliva observa que si se estudia detenidamente esta definición de cultura se puede entender cómo implica irre- 
mediablemente la división entre cultura y naturaleza. División que hoy en día se expresa en la dicotomía ciudad por un lado, naturaleza por otro, donde se presupone que la cuna de la cultura es la ciudad y los ciudadanos, y todo aquel y aquello que quede afuera de la ciudad no puede producir cultura.

La segunda característica de la definición propuesta por el autor, agudiza la distinción entre cultura y naturaleza. Oliva muestra cómo el mismo Aristóteles en su Poética establece claramente que toda obra poética es producción artificial. Así, el relato diegético o narrativo platónico se separa del relato mimético o de representación aristotélico. Para Oliva, desde ese momento y en adelante, se puede sostener que toda cultura es artificio, toda cultura es una producción artificial: "De aquí en adelante, incluso la pregunta sobre si hay algo sustancial o natural, previo a cualquier construcción cultural, parecería ser absurdo" ( $p$ 78).

La tercera característica es la dialéctica entre la cultura como agónica y la cultura como erótica. Sobre esto Oliva dice: "Si la cultura es ontologizada como un ser roto, como 'un comportamiento en ruptura', [...] habrá en ella una nostalgia o añoranza radical". (p. 78) De manera que la cultura se torna en erótica, una erótica muy particular: "Se trata de la violencia extrema de la separación ejemplificada por el arte y, en otra esfera, por el destierro. De hecho, y esto lo ejemplifica muy bien el cristianismo, se trata de la violencia de desprendimiento, una violencia que siempre de forma poética, esto es, artificial, sublima las cosas" (p. 78). Ante la agónica experiencia de la ruptura y la añoranza radical, surge la necesidad erótica de representar artificial y violentamente un mundo.

Una vez establecido esto, Oliva sostiene que está definición de cultura se puede observar o constatar en muchos de los acontecimientos culturales del siglo XXI: "Desde los procesos de neocolonización que han perdido su atalaya civilizatoria, para revelarse como pragmáticos negocios bélico-energéticos, hasta las formas más cotidianas de la violencia y la crueldad que se enmarcan en el hecho cultural: el resurgimiento de la decapitación como forma de justicia en Brasil, en Irak y en México, los feminicidios, los asesinatos y secuestros de niños y niñas en las escuelas rusas [...]" (p. 80), entre otros.

Oliva afirma que este fenómeno se puede entender partiendo del estudio de las naciones y narraciones imperiales desde el siglo XIX. Para ello comienza a trabajar la relación entre imperialismo y cultura a través de un análisis del libro Orientalismo de Said. En éste, el autor se dedica a explorar la tendencia de estos "poetas" occidentales a construir representaciones de las otras culturas. La tesis fuerte, que en este sentido se sostiene, es que la representación que hace el centro, o sea el imperio, de las otras culturas es siempre violenta. Oliva expone y retoma varios ejemplos que de esto hay en el texto de Said. Uno de los casos más viejos de esto, es el de la aparición del personaje Mahoma en 
la Divina comedia de Dante, en donde el profeta musulmán es puesto en el octavo círculo del infierno cumpliendo una condena terrible. Pero Dante no es la excepción sino un antecedente a lo que en el siglo XIX, paralelo a la consolidación de los Estados imperialistas, fue la regla. Oliva menciona las obras Mansfield Park de Jane Austen, Aída de Verdi y Kim de Rudyard Kipling como ejemplos de manifestaciones culturales donde se muestra la consolidación de una visión imperial.

Uno de los puntos centrales que Oliva deriva del estudio del texto de Said es que toda producción cultural contiene una dimensión política. En el caso de los textos producidos desde las naciones imperialistas, el relato político que se incluye a lado de la representación de los otros como seres inferiores a los que hay que civilizar es la justificación de la dominación. El punto es que una representación cultural justifica acciones políticas.

Más adelante, Oliva escribe algunas notas críticas al método de Said y se distancia de la postura poscolonial observando que las condiciones actuales no son las de un imperialismo del siglo XIX. No pretendemos agotar, ni por mucho, el texto de Oliva, sin embargo, para concluir la reseña sobre éste, valdría la pena mencionar solo una de sus muy sugerentes y polémicas "conclusiones violentas o datos culturales":

La cultura es un proceso violento, porque toda representación implica el distanciamiento de algo. Es un axioma elemental, para representar tengo que mirar y reformar las cosas. Así, cualquier manipulación, incluso visual, ya marca un hito violento que puede ir desde la simple violencia del miedo, hasta el hedonismo occidental de las grandes urbes, donde todo tiende a codificarse como mercancía. Tal violencia puede entenderse como un complejo proceso erótico; en el sentido platónico, como un acto de ruptura (p. 91).

El texto Crítica al Estado-nación mexicano de Ambrosio Velasco trata el tema de la nación con relación al conflicto entre el gobierno federal mexicano y el Ejército Zapatista de Liberación Nacional (EZLN). Velasco comienza su texto aportando elementos para comprender la forma "Estado-nación". Ésta es la forma de organización política predominante en la modernidad y rastrea sus orígenes hasta Maquiavelo, quien en El príncipe invita a los Medici a unificar Italia para "librarse de los bárbaros". Así, la promesa con que inicia la forma Estado-nación es la de libertad. Velasco sostiene que a partir de Maquiavelo, el problema que enfrentó la filosofía política moderna fue el de justificar la constitución del Estado.

Para Velasco, la justificación del Estado se ha basado en la apelación a una "nación" y es ahí donde nace el binomio Estado-nación. Sin embargo, hay al 
menos dos formas en que se ha enarbolado como bandera el concepto de nación. Por un lado encontramos a un pueblo en busca de autonomía. Desde este punto de vista la apelación a la "nación" reviste una forma emancipatoria. Por otro lado, un Estado ya constituido también puede apelar al concepto "nación" y esto puede ocurrir a su vez en dos sentidos distintos: a) frente a una potencia extranjera imperialista o intervencionista, en cuyo caso la apelación a la nación toma la forma de una lucha de resistencia y reivindicación, y b) frente a un pueblo, comunidad, cultura o etnia subnacional, en cuyo caso la apelación a la nación toma forma de proyecto de conservación del Estadonación ya constituido y niega las pretensiones de autonomía de dichos grupos subnacionales (pp. 186-187). Así, apelar a la nación justifica proyectos políticos muy distintos, según desde dónde se haga.

Bajo esta perspectiva, Velasco destaca que los movimientos indígenas latinoamericanos de las últimas décadas son casos originales, pues en ellos no se busca una independencia y construcción de un nuevo Estado-nación, sino su redefinición incluyendo el derecho a las autonomías locales. En el caso del EZLN específicamente, Velasco sostiene que la demanda es por "la transformación de una nación homogénea y excluyente, en una nación multiculturalista e incluyente de la diversidad de pueblos y grupos sociales que integran la sociedad mexicana" (p. 187).

Para analizar el conflicto entre el gobierno federal mexicano y el EZLN, Velasco analiza las dos concepciones de nación arriba mencionadas. Una sería la "nación estatal", más común en la modernidad y afín a una postura liberal, donde la "nación" se impone desde el poder político ocupado por algún grupo social, y a veces, por una etnia. La otra sería la "nación cultural", más común en la Antigüedad y más afín a una postura republicana, donde la "nación" surge desde movimientos sociales contestatarios.

Velasco utiliza a diferentes autores para hacer una crítica a la "nación estatal". Por ejemplo, con Gellner, el autor sostiene que la nación moderna es excluyente: "Gellner subraya que la identidad que promueve el nacionalismo como ideología legitimadora de un poder estatal es excluyente de la diversidad originaria [...]" (p. 189). Regresando al caso de México, Velasco nos recuerda que aquí, los excluidos son y han sido los indígenas. Esta situación de exclusión, nos dice el autor, empezó desde la Constitución de Cádiz y la influencia de la ideología de la Revolución francesa en la construcción de una ciudadanía homogénea. Sin embargo, la política de exclusión continuó y se exacerbó a través de los gobiernos independientes, por ejemplo, con las Leyes de Reforma y los proyectos educativos del porfiriato.

En este sentido, el autor sostiene que el EZLN puede entenderse como un movimiento que cuestiona la nación estatal, con el objetivo de promover la 
construcción "desde la sociedad civil [de] otra nación en la que las diferentes etnias y pueblos indígenas puedan vivir juntos" (p. 192).

De la lucha del EzLN el autor trabaja especialmente los Acuerdos de San Andrés Larráinzar (sobre el reconocimiento de los derechos y cultura indígena) entre dicha organización y el gobierno federal. Velasco relata cómo estos acuerdos firmados por ambas partes en 1996 y transformados en propuesta de ley por la Comisión de Concordia y Pacificación (Cocopa), son rechazados por el entonces presidente Ernesto Zedillo. Éste en cambio, elabora una contrapropuesta que no incluye el derecho a la autonomía de los pueblos y minimiza los derechos especiales. Para Velasco, la diferencia entre ambas propuestas de ley, es que los Acuerdos de San Andrés promovían la transformación de la nación de homogénea, excluyente e impuesta a una incluyente y plural. Asimismo, Velasco destaca que el argumento del gobierno federal para rechazar la propuesta de ley Cocopa, fue que ésta y los Acuerdos de San Andrés debilitaban la identidad nacional y propiciaban un proceso de balcanización. El autor muestra así como el argumento del gobierno federal favoreció una concepción de nación estatal liberal.

Velasco relata que en 2001 se formuló otra ley indígena que otra vez tenía un carácter liberal y excluyente y esta sí fue aprobada por el congreso. Sin embargo, también cuenta el proceso de construcción de la autonomía en las comunidades zapatistas con instancias tales como las Juntas de Buen Gobierno cuya función es: "ejerce[r] la autonomía comunitaria para gestionar el desarrollo social con equidad" (p. 196).

La propuesta central de Velasco es la reconstrucción de la nación y con ello la del Estado: "Este esfuerzo por construir una nueva nación mexicana no conduce a una abolición de la democracia ni a la destrucción de la soberanía de la nación. Por el contrario, conduce a la conformación de una auténtica democracia republicana donde la soberanía de la nación es al mismo tiempo la soberanía popular que ha de incluir a todos los pueblos de México" (p. 198).

Ambos textos, como se anunció desde un inicio, tocan el tema de la violencia, uno desde la filosofía de la cultura, otro desde la filosofía política. Tal vez podríamos hallar una coincidencia entre ambos textos. Habría que tomar en cuenta dos cuestiones: a) Oliva nos menciona cómo las manifestaciones culturales de las naciones imperialistas hacen violencia a las otras culturas representándolas de cierta forma para justificar un determinado proyecto de dominación, y b) Velasco muestra cómo la concepción de nación estatal se construye desde el poder del Estado para imponerse sobre los grupos subnacionales en forma, por ejemplo, de una ciudadanía única, provocando, al menos en México, un conflicto violento. Podemos notar que la violencia de la cual ambos textos hablan, tiene una direccionalidad específica: Es ejercida 
por los centros de poder hacia los subordinados. Tal vez al preguntarnos sobre la cotidianidad de la violencia en nuestra vida moderna, habría que preguntarnos por cómo están construidas las estructuras de poder. Creemos, en fin, que ambos textos son una valiosa aportación para reflexionar sobre nuestra realidad, ya que sin duda invitan al debate. 